\title{
A IMPORTÂNCIA DA REALIZAÇÃO DE PROJETOS DE EXTENSÃO COMUNITÁRIA PELO GRUPO PET
}

Karen S. Assis - karenassisassis@gmail.com

Universidade Federal de Santa Catarina

R. Dona Francisca, 8300 - Zona Industrial

89219-600 - Joinville - Santa Catarina

Carlos M. Sacchelli-carlos.sacchelli@gmail.com

Universidade Federal de Santa Catarina

R. Dona Francisca, 8300 - Zona Industrial

89219-600 - Joinville - Santa Catarina

Resumo: É evidente a importância da extensão universitária para aprimorar os desenvolvimentos da comunidade acadêmica. O Programa de Educação Tutorial - PET tem como um dos seus pilares o desenvolvimento de projetos de extensão. Dessa forma, o PET Engenharias da Mobilidade - PET EMB da Universidade Federal de Santa Catarina desenvolve atividades de extensão tanto para a comunidade acadêmica quanto para a comunidade externa. O objetivo dos projetos desenvolvidos é manter um elo entre Universidade e Sociedade como um processo de mudança social e difusão cultural para ambas as partes. Os projetos que serão abordados neste trabalho serão: Campanhas de Conscientização, como setembro amarelo, PET Cultura, projeto criado para fomentar a cultura, AUmigos, ação social visando ajudar animais, Dia das Crianças e Lar de idosos, atividades voltadas para a comunidade externa. Desta maneira o objetivo deste artigo será de relatar alguns projetos realizados, para que possam servir de inspiração para outros grupos PET. Com a realização dos projetos pôde-se concluir que os acadêmicos que participaram das ações, desenvolveram habilidades que são importantes para o mercado de trabalho e formação pessoal, mas que não são desenvolvidas em sala de aula.

Palavras-chave: Extensão universitária. PET. Sociedade. Projetos Sociais.

\section{INTRODUÇÃO}

O programa de Educação Tutorial (PET) é orientado pelo princípio da indissociabilidade entre ensino, pesquisa e extensão. Os estudantes e o tutor do programa têm um compromisso de além de seu desenvolvimento pessoal, do restante da comunidade acadêmica e externa.

O Programa foi criado pela Coordenadoria de Apoio ao Pessoal de Ensino Superior em 1979. (BRASIL, 2018).

Segundo Saraiva (2007) “extensão possibilita ao acadêmico a experiência de vivências significativas que lhe proporciona reflexões acerca das grandes questões da atualidade e, com base na experiência e nos conhecimentos produzidos e acumulados, o desenvolvimento de uma formação compromissada com as necessidades nacionais, regionais e locais, considerando-se a realidade brasileira. Os três fundamentos da universidade, isto é, ensino, pesquisa e extensão, propiciam experiências a discentes e docentes, mas a extensão faz a associação paralela imediata entre o conhecimento científico e o popular". 
A participação dos estudantes em projetos de extensão é de grande importância, pois é uma oportunidade de pôr em prática o que lhe é apresentado em teoria, ajudando na formação cidadã do indivíduo e no desenvolvimento humano, social tornando-se conhecedor dos seus direitos e deveres perante a sociedade.

"Además, se há declarado de manera constante, que la educación superior aspira a formar personas socialmente responsables, donde la enseñanza de habilidades sociales cobra vida propia pues, sin éstas, no es posible lograr el comprometimiento de sus estudiantes con el mundo en que viven". (HERNÁNDEZ, 2013).

A UFSC no campus de Florianópolis apresenta um projeto cultural, conhecido como Projeto 12:30, que existe desde 1993 com apresentações culturais (música, dança e teatro) às quartas feiras durante o horário do almoço. Com o passar do tempo o projeto teve alguns avanços, dentre eles: O Intercâmbio Catarinense, que percorre escolas públicas no interior de Santa Catarina com apresentações musicais seguidas de debate, compartilhando a experiência do projeto e dos músicos com a comunidade local, incentivando a realização de projetos artístico-culturais que promovam a parceria entre artistas e instituições da comunidade; a Gravação de CDs também foi outro desdobramento, em 1999 foi lançado o primeiro CD, com a participação de mais de 60 músicos que gravaram 12 faixas de músicas inéditas, divulgando os melhores momentos do projeto e por fim o Projeto 12:30 na TV. (SILVEIRO, 2015)

O Grupo PET Engenharia Civil do CEFET-MG desde 2016 realiza atividades com o objetivo de contribuir com o desenvolvimento de práticas e experiências pedagógicas para a formação de um Engenheiro Civil ético, cidadão e apto a trabalhar com as demandas atuais do mercado sem perder a sensibilidade e o compromisso com as questões ambientais e a inclusão social. As atividades desenvolvidas são: Jogos Teatrais, Yoga, Dança forró do PET, Sarau poético "Uma noite com Vinícius de Moraes" e Ações Solidarias. (FIALHO, 2019)

Já os acadêmicos de engenharia na Universidade Federal do Pará desenvolvem o projeto de extensão INFOsaberes com o objetivo de promover o conhecimento digital, através da oferta de cursos de Informática Básica e Programação Web, voltados especialmente para pessoas em vulnerabilidade socioeconômica e idosos. O INFOSaberes é realizado em parceria com o Centro de Serviço Social e Educacional da Igreja Evangélica Assembleia de Deus (Templo Central), no município de Ananindeua - PA, onde foi cedido o laboratório de informática para a execução do projeto. As aulas são expositivas e práticas, cada turma é acompanhada por três monitores, um para ministrar a aula e os outros dois para auxiliar mais diretamente os alunos. (LOBATO et al, 2018).

O grupo de alunos voluntários da PUC-Campinas, em parceria com o CRAS-Anhumas, desenvolveu, com o objetivo de levar à parcela mais carente das comunidades de Campinas uma solução de Engenharia Elétrica de baixo custo que permita a iluminação de residências através de um sistema autônomo de iluminação fotovoltaica de baixo custo. (LOPES et al, 2019).

O grupo PET Engenharias do Instituto Federal de Educação, Ciência e Tecnologia da Bahia desenvolve atividades de extensão para a comunidade acadêmica do instituto, dentre elas: Curso de MatLab, Curso de AutoCAD, Curso de Excel, Curso de Licenciatura Ambiental na prática. Essas atividades têm o objetivo de melhorar a formação dos alunos para que eles estejam mais preparados para o mercado de trabalho. Além disso, o grupo tem o projeto Produção integrada de hortaliças pela técnica de Hidroponia com o mecanismo de transformação socioambiental, o projeto visou desperta a consciência ambiental dos jovens e 
o valor da ciência e tecnologia como mecanismo de transformação socioambiental. (RODRIGUES et al, 2019).

Estudantes da Universidade Federal de Ouro Preto, três voluntários e um bolsista, atuam em um projeto de extensão multidisciplinar no Centro Comunitário do Bairro Piedade, em Ouro Preto/MG. As atividades desenvolvidas no Centro são: Reforço escolar, aula de inglês, aula de espanhol, brincadeiras, oficinas, minicursos, Ballet, aula de violino e Capoeira. O projeto tem o intuito de melhorar o desenvolvimento e o aprendizado escolar dos alunos. (SILVA, et al, 2019).

Os exemplos citados anteriormente são apenas alguns projetos sociais de instituições de ensino, mostrando a grande importância da interação entre as instituições, do corpo discente e docente com a comunidade externa. Servindo de inspiração para a proposição de projetos pelo grupo PET EMB.

Em 2019, o grupo PET EMB da Universidade Federal de Santa Catarina, observou que devido a rotina pesada de estudos vários estudantes apresentavam depressão, auto cobrança e estresse. Segundo Moretti e Hubner (2017)," a rotina acadêmica interfere de forma impactante no estresse dos acadêmicos e que uma nova política educacional deve ser trabalhada visando progressos nas estruturas curriculares, que acabam por massacrar os estudantes".

Com isso o grupo PET EMB além de desenvolver atividades culturais e várias campanhas sociais e de conscientização, também abordou temas de bem estar e saúde com o intuito de melhorar o dia a dia da comunidade acadêmica. Assim, o objetivo principal deste artigo será de relatar alguns projetos realizados, para que possam servir de inspiração para outros grupos PET.

\section{PROJETOS REALIZADOS}

As atividades realizadas pelo PET EMB em 2019 foram voltadas tanto para a comunidade acadêmica quanto para a comunidade externa, com o objetivo de auxiliar e aprimorar os conhecimentos dos discentes e de fazer uma troca de aprendizado com a comunidade externa.

No início de cada semestre é realizada uma reunião com todos os membros do grupo para que seja apresentado os projetos que serão desenvolvidos. Nessa reunião é escolhido os membros que participarão de cada projeto, sempre temos um ou dois responsáveis por projeto e alguns ajudantes, a escolha da quantidade de membros em cada atividade é de acordo com o nível de dificuldade de realização do mesmo.

O planejamento de cada projeto é feito pelo seu responsável e as atividades são divididas entre os membros que estão participando. Em atividades para a comunidade acadêmica, temos um prazo de no mínimo quinze dias para a divulgação, com o intuito de alcançar a maior adesão possível.

Ao final de cada projeto enviamos um formulário por meio da plataforma google forms tanto para os membros que participaram da realização, sejam eles petianos ou não, quanto para o publico alvo. Neste formulário recolhe-se dados do que foi positivo ou negativo e pede-se sugestões do que pode melhorar na próxima realização. Em alguns casos, como na ação social realizada com idosos ou crianças, não é viável a aplicação do formulário. Dessa forma, o levamento de dados do resultado é feito com os responsáveis pela instituição por meio de depoimentos.

O intuito do formulário, além de visar a melhoria do projeto, é ver o nível do desenvolvimento dos petianos em suas habilidades: compromisso, responsabilidade, empatia, 
tomada de decisões, comunicação, gerenciamento e liderança. Cada membro faz a sua autoavaliação e avalia os seus parceiros no projeto também. As avaliações são feitas de forma anônima e depois discutidas em uma reunião no final do semestre.

Dentre os projetos desenvolvidos têm-se: Campanhas de Conscientização, Bem estar, Sociais e Culturais. Na sequência será relatado alguns destes projetos.

\subsection{Campanhas de conscientização e sociais}

Mediante aos projetos realizados pelo grupo PET EMB e os feedbacks que foram apresentados, pode-se comprovar que as atividades de interação entre os discentes e de solidariedade apresentam um efeito positivo na sociedade.

Com o intuito de conscientizar o campus da UFSC Joinville, uma série de campanhas de conscientização e sociais foram planejadas para acontecer no decorrer do ano de 2019 em alguns meses específicos.

Ocorreram, por exemplo, campanhas para o combate a violência contra a mulher em agosto (Figura 1), divulgação de informações sobre a depressão e demais problemas relacionados a saúde emocional e psicológica em setembro e conscientização sobre o câncer de mama em outubro.

Foi observado a adesão da comunidade acadêmica a nossas iniciativas; por meio da participação dos alunos em palestras, aulas e o compartilhamento das nossas informações nas redes socias; principalmente durante o agosto lilás (combate a violência contra a mulher) e setembro amarelo (combate ao suicídio), duas pautas infelizmente que mais se encontram presentes em nosso meio universitário, que pode se apresentar algumas vezes como misógino e opressor.

Durante o setembro amarelo (Figura 2) foram desenvolvidos algumas atividades além da campanha visual, sendo realizado uma roda de conversa com a psicóloga do campus em parceria com a Assistência estudantil e uma aula de Body Balance (aula que trabalha o corpo e a mente em movimento e que aborda: Tai Chi Chuan, arte macial, ritmo calmo, flexibilidade postural e movimentos, yoga, força, core e relaxamento). (Figura 3)

A aula foi ministrada pela professora Thayanni Vilela, credenciada pela Les Mills em Body Balance, com a participação de onze discentes, a discente Mayra Silvyane fez um relato sobre a sua participação na aula:

"A aula me ajudou muito, eu tive uma prova após aquela dinâmica, e eu fui mais tranquila e relaxada fazer meu teste, às vezes só precisamos de alguém para nos dar uma motivação que nem sempre vem com as palavras ditas. Eu adorei a iniciativa do PET em querer ajudar os alunos em prol a campanha do setembro amarelo, gostaria muito que a faculdade incentivasse e encorajasse seus acadêmicos a ajudarem em projetos como esses e participarem dessas aulas de alongamento, relaxamento, uma roda de conversa e que isso fizesse parte do nosso cotidiano, pois nos ajudaria a relaxar tirando essa pressão e tensão que sentimos por conta da dificuldade que há nos cursos. Somos seres humanos e não robôs acadêmicos, falo por mim, gostaria de estar em um ambiente que se importasse um pouco mais com meu psicológico e não, somente, com minhas notas. Obrigada PET por promover dias melhores a uma universitária”.

As campanhas tiveram como finalidade de levar apoio e conscientização a toda a comunidade Nas Figuras 1 e 2 se observam o Hall principal da Universidade com balões e cartazes indicando a campanha que estava sendo realizada. 


\section{COBENCE de Educaçāo em Engenharia

Figura 1: Agosto Lilás

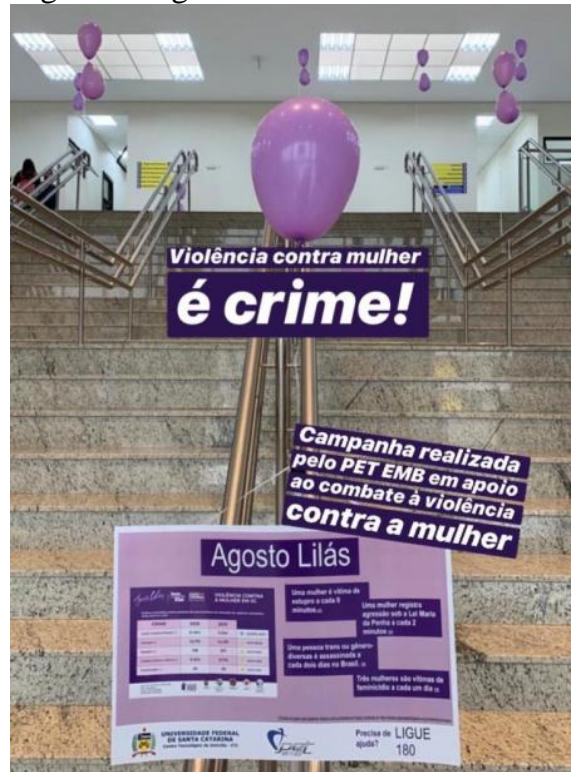

Fonte: Autor
Figura 2: Setembro Amarelo

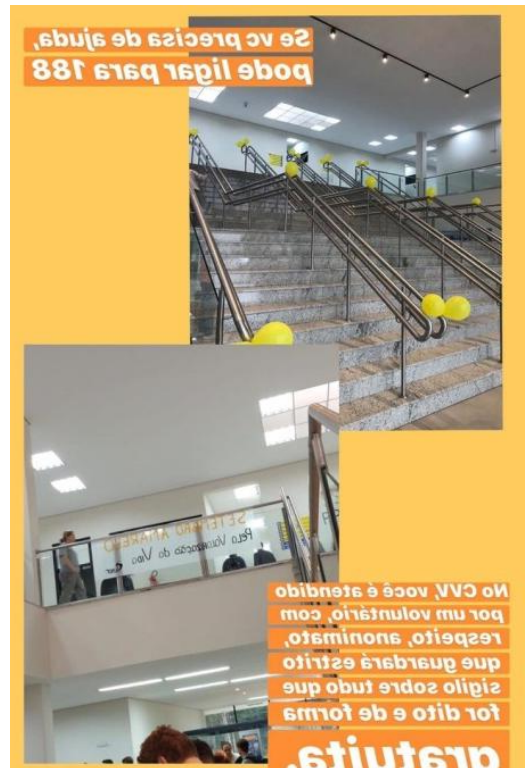

Fonte: Autor

Figura 3: Aula de Body Balance

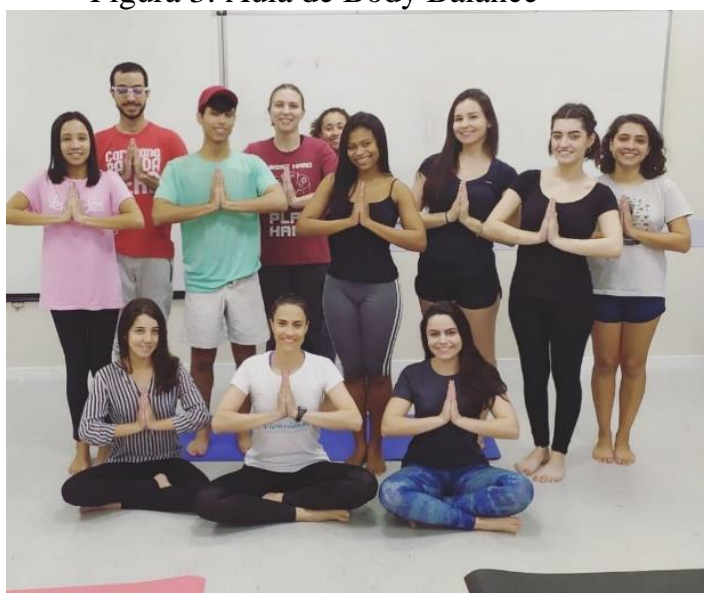

Fonte: Autor

\subsection{Ações culturais}

O PET Cultura é um projeto criado em outubro de 2019, com o objetivo de trazer algo novo e fora do cotidiano dos estudantes de engenharia para aliviar a pressão na rotina de estudos e dias cansativos dentro da Universidade. O projeto foi desenvolvido durante o mês de outubro, meio do semestre, com o desenvolvimento de uma tela comunitária, jogo de queimada, mostra de talentos e exposição de fotos e poemas.

A exposição de fotos (Figura 4) e poemas dos próprios discentes, docentes e servidores aconteceu durante todo o mês de outubro. Foi publicado nas redes sociais e no e-mail institucional o período de uma semana para que fosse feita entrega do material que cada um gostaria de expor. Depois disso os bolsistas do PET montaram um mural com os poemas e um varal com as fotos e ambos foram expostos no hall de entrada da universidade.

Durante a segunda semana do mês foi realizada a mostra de talentos no horário do almoço, a interação entre os discentes foi positiva e a disponibilidade para as apresentações 
também. Para realizar essa atividade os membros do PET tiverem o auxílio de um acadêmico de outra entidade estudantil que já havia realizado atividade semelhante, e o apoio da Universidade com a disponibilização dos equipamentos necessários.

A atividade de pintura de uma tela de forma comunitária, na qual o plano era deixá-la exibida aos alunos para que todos pudessem pintar a tela da forma que quisessem durante uma semana, porém a atividade foi concluída em um único dia. Os discentes solicitaram que fosse disponibilizado outras telas, mas o projeto seria com uma tela apenas por semestre. Depois de finalizada a tela foi colocada no hall de entrada da Universidade. (Figura 5)

A realização do jogo da queimada (Figura 6) também foi durante o almoço, e mesmo o tempo sendo corrido e a quadra, onde a atividade foi realizada, sendo exposta ao sol a atividade teve uma participação muito boa. A atividade funcionava com a divisão de dois times e com uma bola um time ficava arremessando a bola no outro com o intuito de acerta um dos membros, e a equipe que conseguisse acertar todos os membros da outra equipe era vencedora.

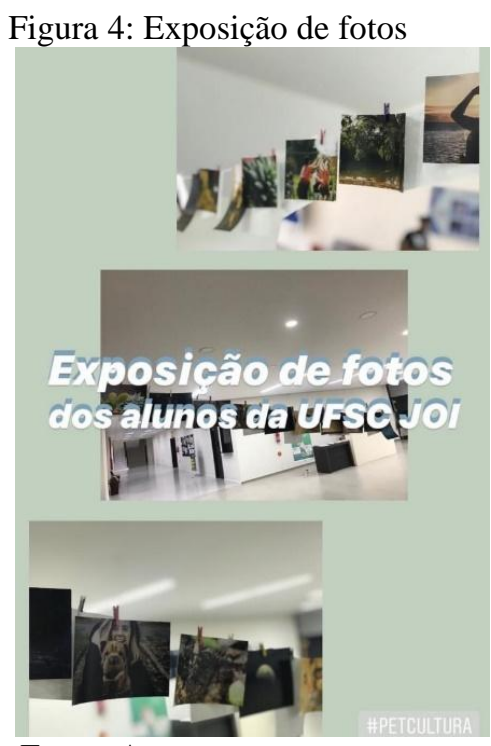

Fonte: Autor

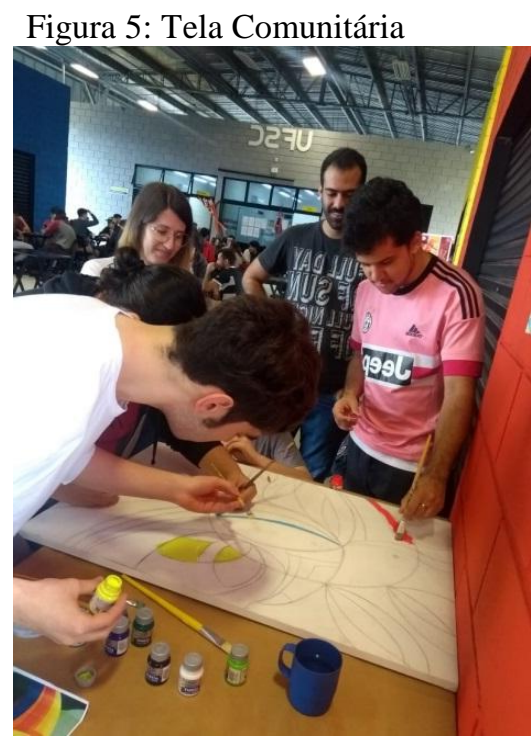

Fonte: Autor

Figura 6: Queimada

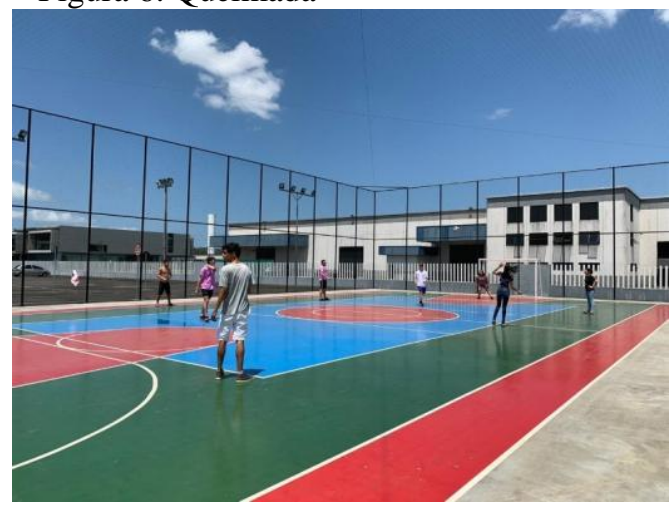

Fonte: Autor

\subsection{AUmigos}

A AUmigos foi uma ação social desenvolvida pelo grupo PET com o objetivo de ajudar o Abrigo Animal de Joinville, que é uma organização não governamental e sem fins lucrativos, 
mantida através de doações para providenciar atendimento veterinário, vacinação, castração e alimentar mais de 300 cães que consomem diariamente $90 \mathrm{~kg}$ de ração.

A ação aconteceu em duas etapas, a primeira etapa foi a campanha de arrecadação de ração para os cachorros, para a compra de ração de boa qualidade. Além das doações da Universidade, o PET EMB participou de uma oficina de liderança com a empresa Somar Pessoas, sendo o valor arrecadado doado para a ação. A segunda etapa foi a entrega das arrecadações e um passeio com os cachorros que estão à disposição uma vez por mês para que qualquer pessoa possa passear com eles.

Na Figura 7 observamos as rações compradas e na Figura 8 um cachorrinho da ONG.

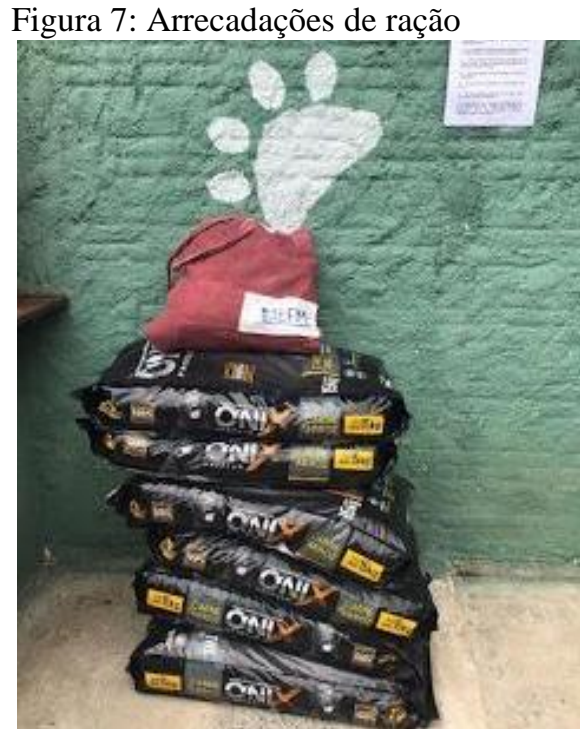

Fonte: Autor
Figura 8: Cachorro da ONG

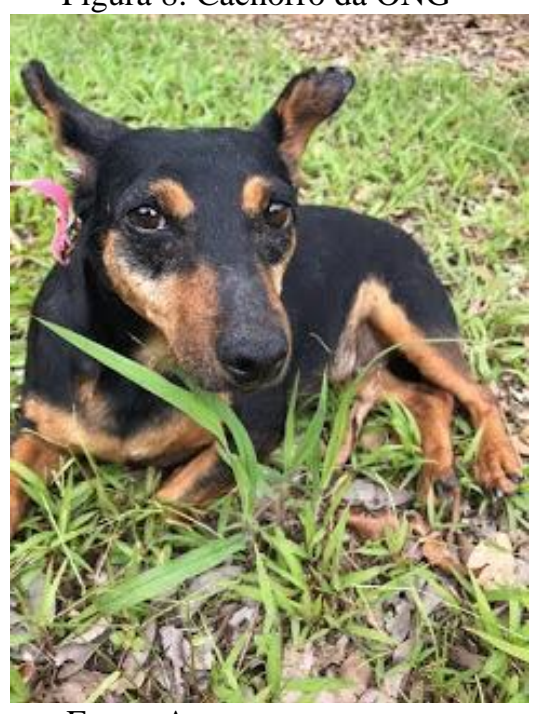

Fonte: Autor

\subsection{Dia das crianças}

O projeto do dia das crianças acontece desde 2017. Os petianos trabalham nessa ação sempre em conjunto com uma ONG, em 2017 e 2018 o projeto aconteceu em parceria com a ONG Projetando Felicidade. Membros do PET EMB participam do projeto auxiliando nas arrecadações de alimentos para serem preparados no dia do evento, arrecadações de brinquedos, na procura de voluntários para apoiar no dia do evento e no desenvolvimento de oficinas.

Dentre as oficinas desenvolvidas tem-se: Oficina de brinquedos recicláveis, pintura de rosto, desenho e pintura, oficina de origami (Figura 9).

\subsection{Lar de idosos}

O projeto Lar de idosos foi criado no primeiro semestre de 2019 pelo PET EMB, com o intuito de proporcionar uma tarde de distração para os idosos. Foram selecionados dois lares na cidade de Joinville para o desenvolvimento do projeto, o grupo PET convidou outras entidades estudantis da UFSC no campus de Joinville para que o projeto fosse desenvolvido na melhor forma possível. 


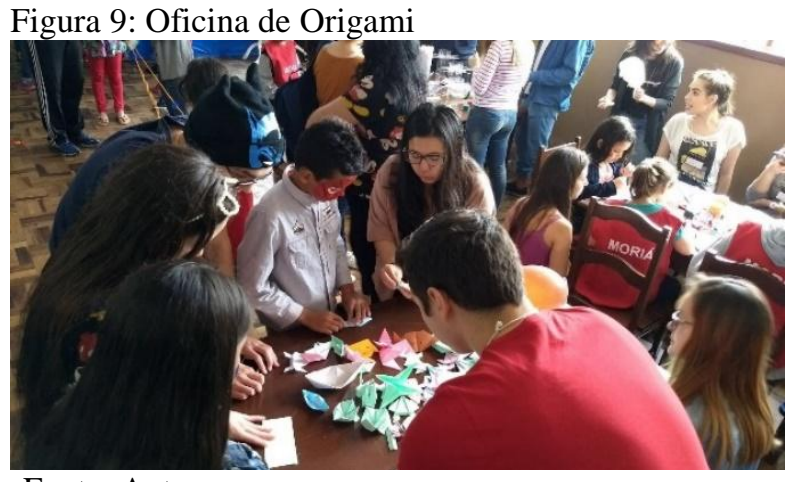

Fonte: Autor

Umas das etapas do projeto foi a arrecadação de produtos de limpeza, higiene pessoal e alimentos para o lar. Toda a comunidade acadêmica ajuda bastante nessa etapa, principalmente o corpo docente, membros das outras entidades fazem a arrecadação nos locais onde residem e são disponibilizados pontos de coleta dentro da própria Universidade.

Antes da primeira visita, foi preparado um roteiro de possíveis atividades a serem realizadas com os idosos por uma professora da UFSC, doutora e mestre em Psicologia, levando em consideração as dificuldades que alguns deles apresentavam. Durante a visita poucas atividades foram desenvolvidas, pois poucos deles estavam dispostos a fazer. Ficou claro que eles queriam atenção, alguém para escutar as suas histórias e interagir com eles. A atividade que apresentou maior sucesso foi uma roda de música com violão, em que alguns deles até se voluntariaram a dançar.

O projeto foi bem aceito pela comunidade acadêmica, mediante a quantidade de arrecadações e disponibilidade para ajudar no dia da visita, e realizado novamente no segundo semestre nos mesmos lares de idosos (Figura 10 e 11). Alguns idosos lembraram dos estudantes que haviam ido na primeira vez e a interação foi ainda maior.

Figura 10: Lar Anjo Gabriel

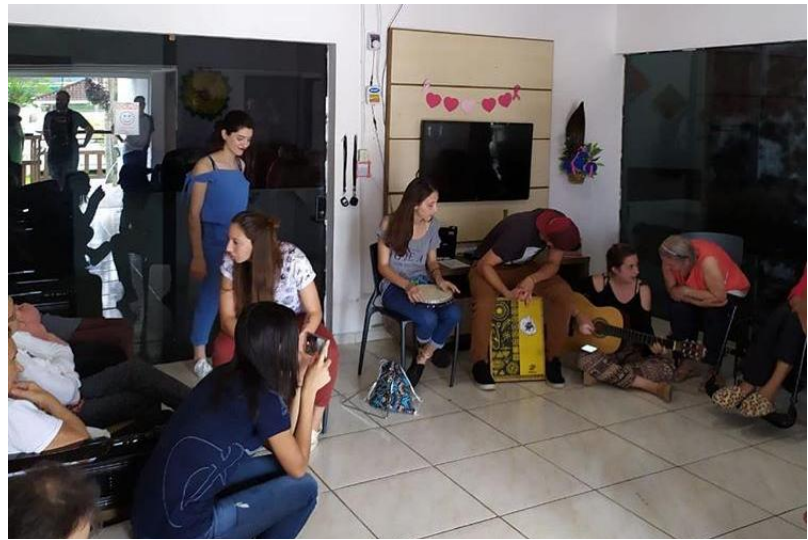

Fonte: Autor
Figura 11: Arrecadações

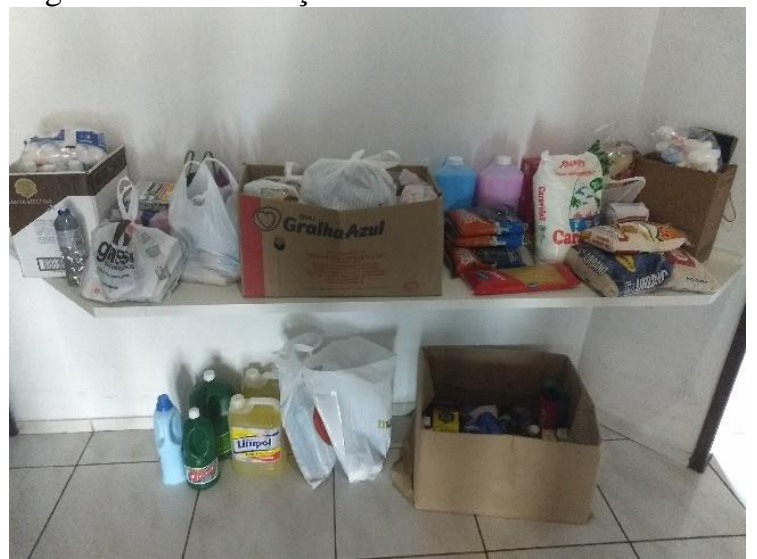

Fonte: Autor 


\section{CONSIDERAÇÕES FINAIS}

Mediante aos projetos realizados pelo grupo PET EMB e os feedbacks que foram apresentados por meio de formulário ou depoimentos, pode-se comprovar que as atividades de interação entre os estudantes e a sociedade apresentam um efeito positivo para ambos.

As atividades realizadas contribuem para o desenvolvimento de habilidades comportamentais para os membros do PET, que são importantes para o mercado de trabalho, tais como: trabalho em equipe, liderança, proatividade, comunicação, formação de cidadãos conscientes e sociáveis.

Para a comunidade externa as atividades desenvolvidas são essenciais para reafirmar o sentido de cidadania dessa parte da população que de certo modo é deixada de lado.

As campanhas de conscientização e sociais e o projeto cultural foram importantes para reafirmar a preocupação de entidades estudantis com toda a comunidade acadêmica e ressaltar a inclusão social que se faz tão necessária em toda a sociedade.

Todas as atividades apresentadas foram realizadas durante o ano de 2019 e os petianos planejam dar continuidade e aprimorar as mesmas com o retorno do semestre.

\section{Agradecimentos}

Os autores agradecem o Ministério da Educação e ao FNDE pela oportunidade da bolsa dentro do Programa de Educação Tutorial - PET. À universidade pelo apoio ao programa e apoio ao nosso projeto.

\section{REFERÊNCIAS}

BRASIL. Ministério da Educação. Governo Federal do Brasil (org.). Apresentação - PET. 2018. Disponível em: http://portal.mec.gov.br/pet. Acesso em: 20 abr. 2020.

FIALHO, Patrícia, et al. Atividades de Interação, Autoconhecimento e Solidárias promovidas pelo grupo PET Engenharia Civil do CEFET-MG. In: XLVII Congresso Brasileiro de Educação em Engenharia e II Simpósio Internacional de Educação em Engenharia da ABENGE, 2019, Ceará. Anais. Fortaleza, 2019.

HERNÁNDEZ, Mayra Ordaz. La educación de habilidades sociales desde la Extensión Universitaria. Propuesta de acciones. Educar em Revista, Curitiba, Brasil, n. 50, Editora UFPR, out./dez 2013, pp. 269-283;

LOBATO, Elen, et al. Infosaberes: Um projeto de inclusão social através da inclusão digital. In: XLVI Congresso Brasileiro de Educação em Engenharia e $1^{\circ}$ Simpósio Internacional de Educação em Engenharia, 2018, Salvador. Anais. Bahia, 2018.

LOPES, Bruna, et al. Participação Voluntária em Projetos de Extensão- Desenvolvendo Competências através da Engenharia Social. In: XLVII Congresso Brasileiro de Educação em Engenharia e II Simpósio Internacional de Educação em Engenharia da ABENGE, 2019, Ceará. Anais. Fortaleza, 2019.

MORETTI, Felipe Azevedo; HUBNER, Maria Martha Costa. O estresse e a máquina de moer alunos do ensino superior: vamos repensar nossa política educacional?. Rev. psicopedag. São Paulo, v. 34, n. 105, p. 258-267, $2017 . \quad$ Disponível em: <http://pepsic .bvsalud.org/scielo 
"Os desafios para formar hoje o engenheiro do amanhã"

.php?script=sci_arttext\&pid=S010384862017000300003\&lng=pt\&nrm=iso $>$. Acesso em 01 maio. 2020.

SARAIVA, J. L. Papel da Extensão Universitária na Formação de Estudantes e Professores. Brasília Médica, Brasília, v. 44, n. 3, p. 220-225, 2007.

RODRIGUES, Marília A., et al. Atividades Desenvolvidas pelo grupo PET Engenharias no Instituto Federal da Bahia Campus Vitória da Conquista. In: XLVII Congresso Brasileiro de Educação em Engenharia e II Simpósio Internacional de Educação em Engenharia da ABENGE, 2019, Ceará. Anais. Fortaleza, 2019.

SILVA, Vanessa F., et al. Análise do Perfil do grupo familiar dos estudantes que frequentam o projeto de Extensão Universitária em centro cultural. In: XLVII Congresso Brasileiro de Educação em Engenharia e II Simpósio Internacional de Educação em Engenharia da ABENGE, 2019, Ceará. Anais. Fortaleza, 2019.

SILVERIO, Renata; NUNES, Rogério. Cultura na Universidade: O Projeto 12:30 da Universidade Federal de Santa Catarina. In: XV Colóquio Internacional de gestão Universitária-CIGU, 2015, Mar del Plata. Repositório. Argentina, 2015.

\section{THE IMPORTANCE OF COMMUNITY EXTENSION PROJECTS}

Abstract: The importance of university extension in the academic environment is evident to improve the developments of the academic community. PET (Tutorial Education Program) has as one of its pillars the development of extension projects. Thus, the PET EMB of the Federal University of Santa Catarina develops extension activities for both the academic community and the external community. The objective of the developed projects is to maintain a link between University and Society as a process of social change and cultural diffusion for both parties. The projects that will be addressed are: Social Campaigns, with yellow September, PET Cultura, a project created to foster culture; AUmigos, social action to help animals; Children's Day and Nursing Home, activities aimed at the external community. Thus, the objective of this article will be to report on some projects that have been carried out, so that they can serve as inspiration for other groups to also carry out. With the realization of the projects it can be concluded that students developed skills that are important for the job market and personal training, but that are not developed in the classroom.

Keywords: University Extension. PET. Society. 